\title{
UPDATING OBJECT FOR GIS DATABASE INFORMATION USING HIGH RESOLUTION SATELLITE IMAGES: A CASE STUDY ZONGULDAK
}

\author{
M. Alkan ${ }^{1, *}$, D. Arca ${ }^{1}$, Ç. Bayik ${ }^{1}$, A.M. Marangoz ${ }^{1}$ \\ ${ }^{1}$ Zonguldak Karaelmas University, Engineering Faculty Geodesy and Photogrammetry Department- \\ mehmetalkan44@yahoo.com, (denizkayabasi86, caglarbayik, aycanmarangoz)@ hotmail.com
}

KEYWORDS: GIS, Remote Sensing, High resolution imagery, Object Extraction.

\begin{abstract}
:
Nowadays Geographic Information Systems (GIS) uses Remote Sensing (RS) data for a lot of applications. One of the application areas is the updating of the GIS database using high resolution imagery. In this context high resolution satellite imagery data is very important for many applications areas today's and future. And also, high resolution satellite imagery data will be used in many applications for different purposes. Information systems needs to high resolution imagery data for updating. Updating is very important component for the any of the GIS systems. One of this area will be updated and kept alive GIS database information. High resolution satellite imagery is used with different data base which serve map information via internet and different aims of information systems applications in future topographic and cartographic information systems will very important in our country in this sense use of the satellite images will be unavoidable. In this study explain to how is acquired to satellite images and how is use this images in information systems for object and roads. Firstly, pan-sharpened two of the IKONOS's images have been produced by fusion of high resolution PAN and MS images using PCI Geomatica v9.1 software package. Automatic object extraction has been made using eCognition v4.0.6. On the other hand, these objects have been manually digitized from high resolution images using ArcGIS v9.3. software package. Application section of in this study, satellite images data will be compared each other and GIS objects and road database. It is also determined which data is useful in Geographic Information Systems. Finally, this article explains that integration of remote sensing technology and GIS applications.
\end{abstract}

\section{INTRODUCTION}

Nowadays, Remote Sensing technology has the availability of high resolution optical imagery appears to be interesting for geo-spatial database applications, namely for the capturing and maintenance of geodata. Recent works show that the geometry Ikonos imagery are accurate enough for mapping purpose up to scale of 1:5000 (Büyüksalih and Jacobsen, 2005). Mapping today is a data acquisition for GIS. Maps are just one form of the geoinformation (Jacobsen et.all, 2008). High resolution satellite imagery data has a lot of advantages and they can be used for updating the available maps in GIS software packages. GIS is very important tool for design and development for the a lot of geomatic applications and the other areas. GIS is needs to update data for living of the GIS database. For this reason, a lot of high resolution satellite imagery has been used for the updating procedure of the GIS database. Very high resolution space images such as QuickBird are available for the generation of mapping and remote sensing applications and used as an alternative means to aerial photographs. Also, important research aims have mostly been to detect and document urban vegetation and green areas from urban sites, then to determine the size of topography covering the area and to make temporal analysis so that public utilities such as newpark areas can be planned and new arrangements can be made at these urban sites (Marangoz et.all, 2007).

In this study, vectors produced automatically and manually have been compared with the existing topographing maps and reference vector maps of scale 1/5000 of test area. Classification procedure has been implemented using pan-sharpened IKONOS images of the interest area. Such an image can be easily formed by the pan-sharpening module of PCI Geomatica 9.1.1 system. The success of object-oriented image analysis results was tested by GIS software; the results have been presented and commented. Several tests have been carried out to match with the successful segmentation, then the classification by entering different parameters to the used software. Automatic object-based classification of buildings and roads in the Zonguldak study area of Turkey has been realized by eCognition v4.0.6 software. In addition, based on the previous studies, road network from pan-sharpened IKONOS images of the same area has been extracted using GIS software and the extracted manually results has been given and interpreted. Therefore, making GIS-based analysis and comparisons with raster and vector data of the test area has crucial importance in terms of putting forth the recent situation. Finally, aim of this study is to updating GIS database procedure test using feature extraction capacity of this high resolution images. The results obtained have changed into vector format and integrated to a database.

\section{STUDY AREA}

Zonguldak is a coal mining city which is located in Western Black Sea region of Turkey. Test area of Zonguldak has very rough and mountainous topography that's why terrain inclination has a big influence on the accuracy of the results. Figure 1 and figure 2. shows the Ikonos space images of study area. At the upper side of the image, in the white circle, the city centre and harbour can be seen. The mountainous topography is obvious and the narrows show the highest terrain. The mountainous topography is obvious and the narrows show the highest 
International Archives of the Photogrammetry, Remote Sensing and Spatial Information Sciences, Volume XXXVIII-4/W19, 2011 ISPRS Hannover 2011 Workshop, 14-17 June 2011, Hannover, Germany

terrain. the elevations reach $1646 \mathrm{~m}$ and the average terrain inclination is \%23 (Sefercik et all., 2008). In the upper part of image, Black Sea is lying down and other parts of the image include central part of the Zonguldak city which covers nearly $15 \times 15 \mathrm{~km}$ area with the elevation range up to $450 \mathrm{~m}$. After geometric correction of IKONOS imageries (Jacobsen et all., 2005), it was enhanced by applying a pan-sharpening method (Zhang and Wang, 2004) used in PCI system. This method makes it possible to benefit from the sensors spectral capabilities simultaneously with its high spatial resolution.

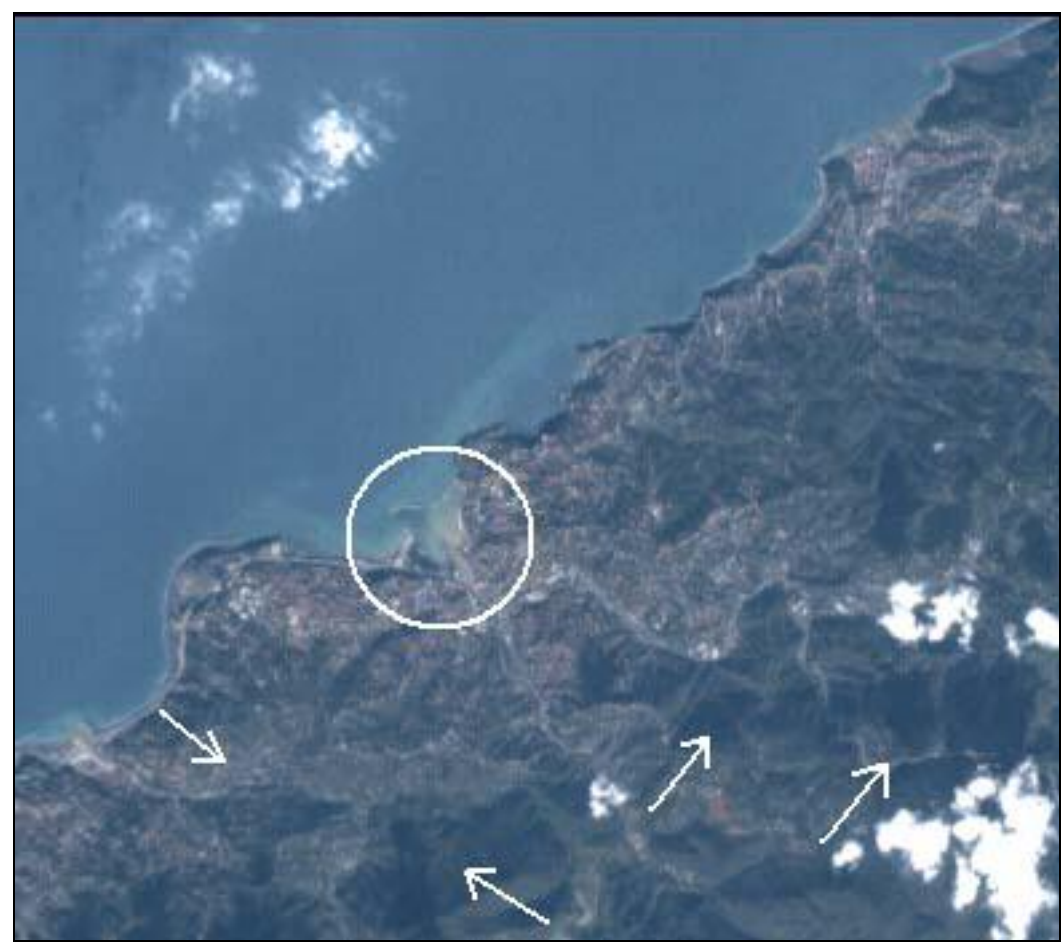

Figure 1. IKONOS images of Zonguldak test area which is taken 2002.

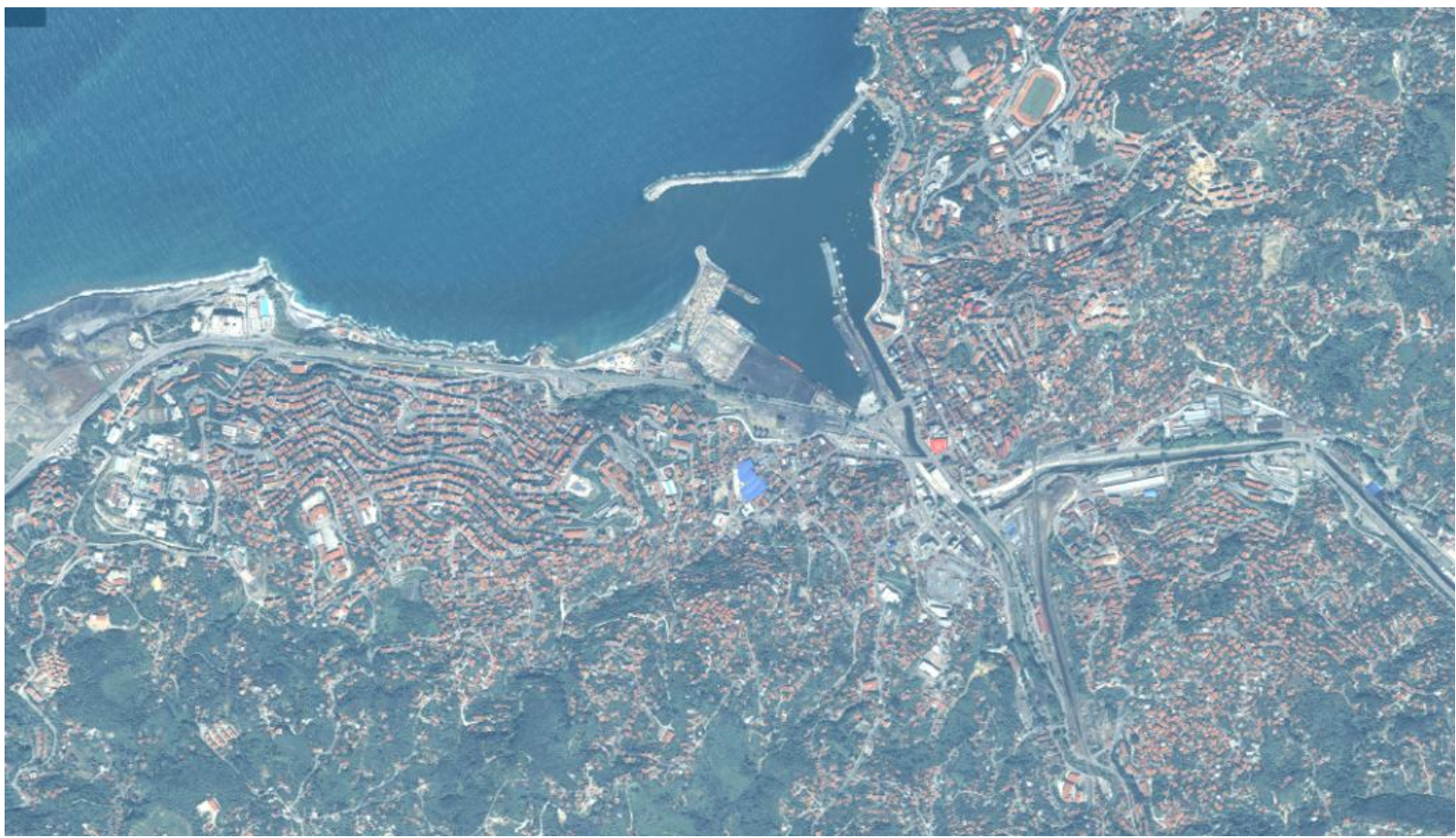

Figure 2. Subset of Pan-sharpened IKONOS-2008 Image of Zonguldak Study Area 


\section{GIS DATABASE}

In this part GIS database design was executed. There are four main objects were selected for database design. Firstly, requirement analysis were executed for the designing and implementing database structure. General database design shows on figure 3 . In the database design, every objects were maintained in different tables.
Figure 3 shows a portion of the database schema. In these tables, relatively constant data, such as parcel area, building_id, flat number, road_id and others are stored. Thus, the only relevant information is changed when, e.g., a building is demolish or constructed and also every update of the general information; in this way, repetition of data is avoided.

PARCELS
\begin{tabular}{|l|l|l|l|l|l|l|l|}
\hline & & & & & & & \\
Parcel_id & City & Town & District & Section & Parcel_No & $\ldots .$. & t_min \\
\hline & & & & & & & \\
\hline
\end{tabular}

BUILDINGS

\begin{tabular}{|l|l|l|l|l|l|}
\hline$\underline{\text { Parcel id }}$ & Build id & Condominums & Flat_Number & $\ldots . .$. & tmin \\
\hline & & & & & \\
& & & & & \\
\hline
\end{tabular}

\section{ROADS}

\begin{tabular}{|l|l|l|l|l|l|}
\hline Parcel_id & Road_id & RoadName & tmin & $\ldots . .$. & Construction_date \\
\hline & & & & & \\
& & & & & \\
\hline
\end{tabular}

OTHER OBJECTS

\begin{tabular}{|l|l|l|l|l|l|l|}
\hline Tas id & Object id & Object_No & Carnal & $\ldots .$. & tmin & Others \\
\hline & & & & & & \\
\hline
\end{tabular}

Figure 3. A portion of the database schema.

\section{RESULTS AND DISCUSSION}

Object-based approach takes the form, textures and spectral information into account. Its classification phase starts with the crucial initial step of grouping neighboring pixels into meaningful areas, which can be handled in the later step of classification. Such segmentation and topology generation must be set according to the resolution and the scale of the expected objects. By this method, not single pixels are classified but homogenous image objects are extracted during a previous segmentation step. This segmentation can be done in multiple resolutions, thus allowing differentiating several levels of object categories (Baatz et all., 2004). For the purpose of this study, several tests were carried out to match with the successful segmentation, then the classification by entering different parameters to eCognition software package (Fig. 4.). Manual extraction has been executed on ArcGIS software packages. All of the object details can be extracted for this manual methods. Comparable results will be seen figure 5. and figure 6 . These results shows difference between IKONOS imageries and 1:5000 scale topographic maps (reference vector maps). 


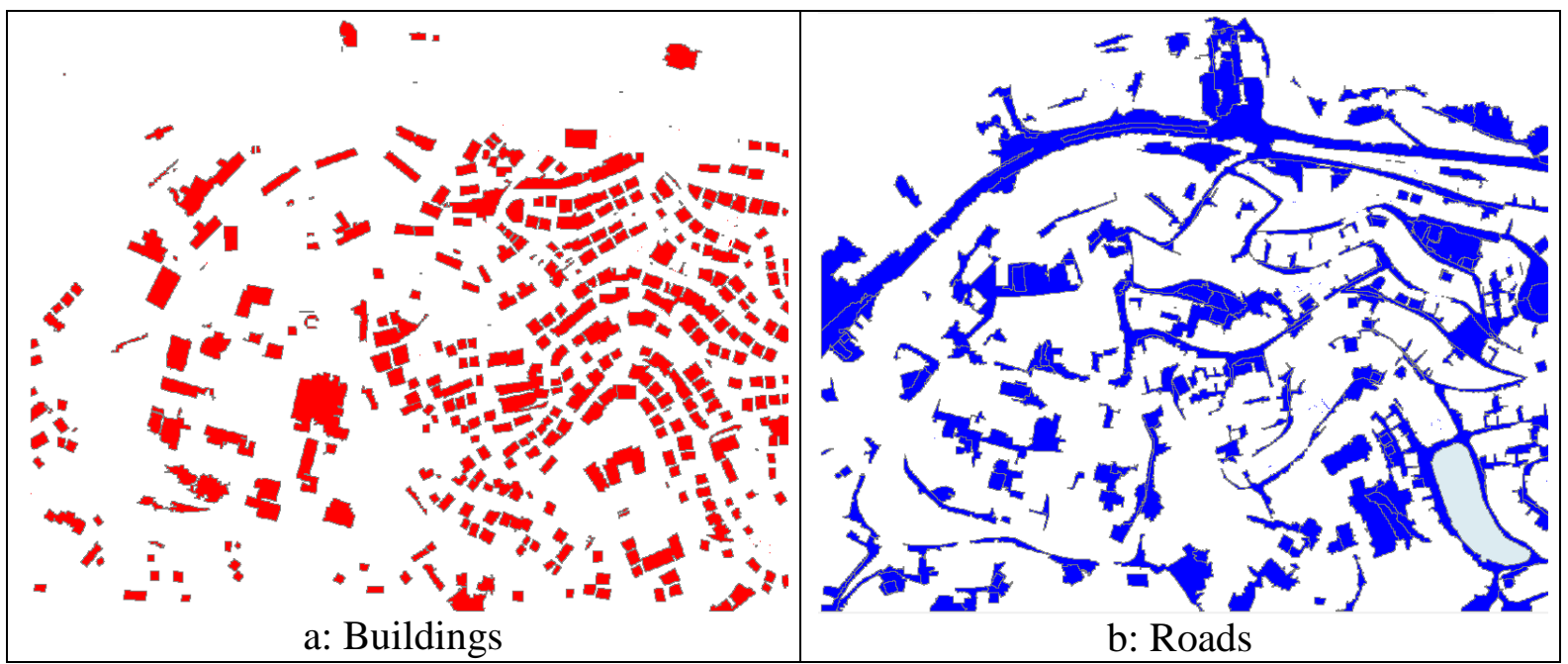

Figure 4. Vector results of object-based classification of building (a) and road network (b) from Ikonos (2008) image

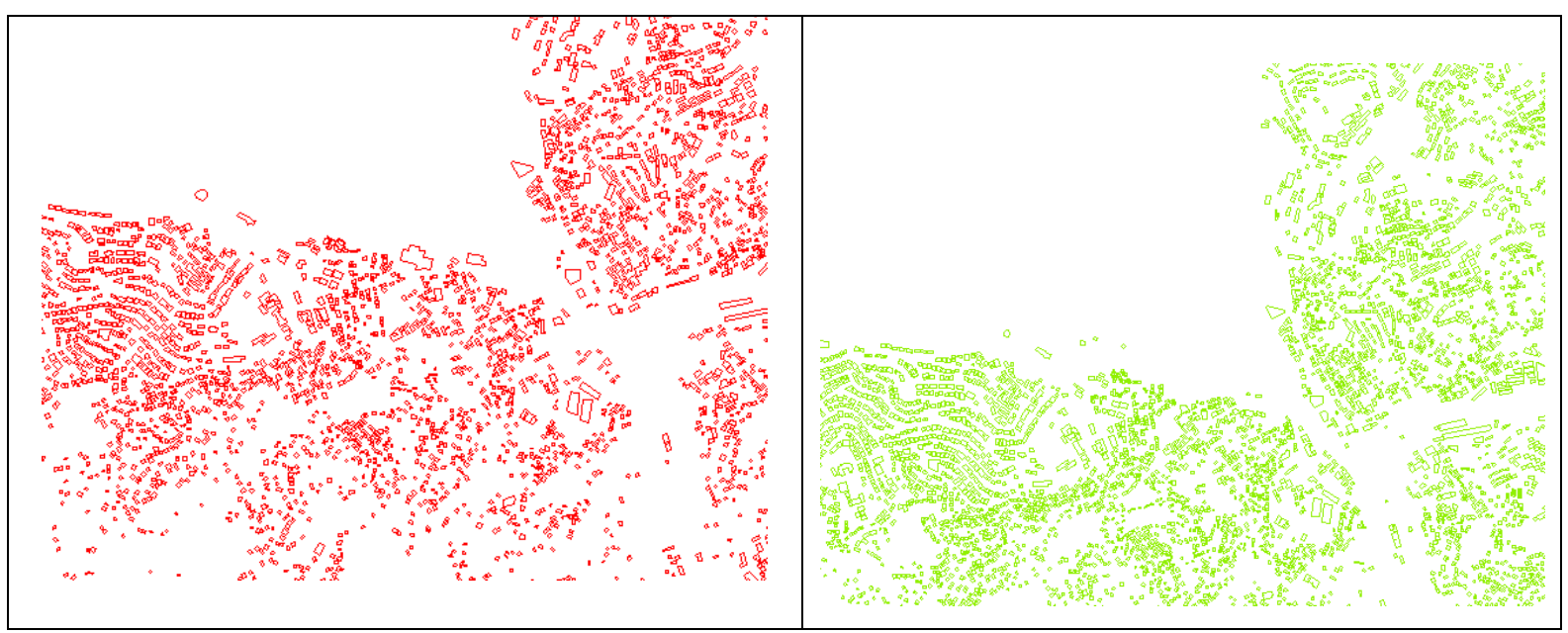

Figure 5. GIS Based analysis of on-screen manual digitizing results of the building from IKONOS-2002 image (left) and reference vector (right)

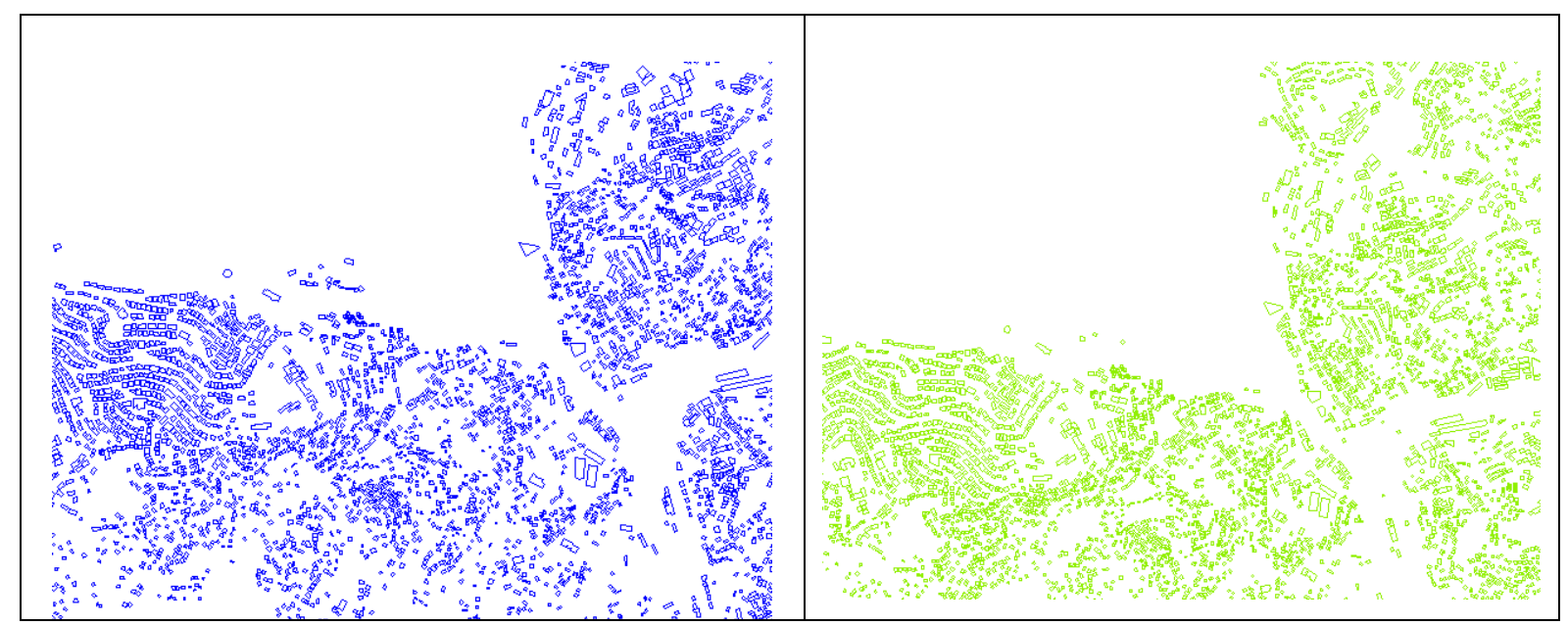

Figure 6. GIS Based analysis of on-screen manual digitizing results of the building from IKONOS-2008 image (left) and reference vector (right)

Depends on the GIS analysis, IKONOS-2002 images have a 6524 numbers of buildings. IKONOS-2008 images have a 7592 buildings and finally $1 / 5000$ scale maps have a 6937 buildings. For the GIS analysis, it is 
very easy to trace of the comparison and also changes of the building database. On the other hand, it is very important component is ratio of the manual extraction results from the High resolution imageries. In this study, building extraction capability is $\% 76$, road extraction capability is $\% 73$ from IKONOS imageries. Other results from imageries and 1/5000 scale maps road extraction. As a results of this, IKONOS-2002 have a $52003 \mathrm{~m}$, IKONOS-2008 $113.021 \mathrm{~m}$ and 1/5000 scale map have a $75203 \mathrm{~m}$ road distance. It is possible to seen on figure 7 . of road database for IKONOS imageries on the ArcGIS interface.

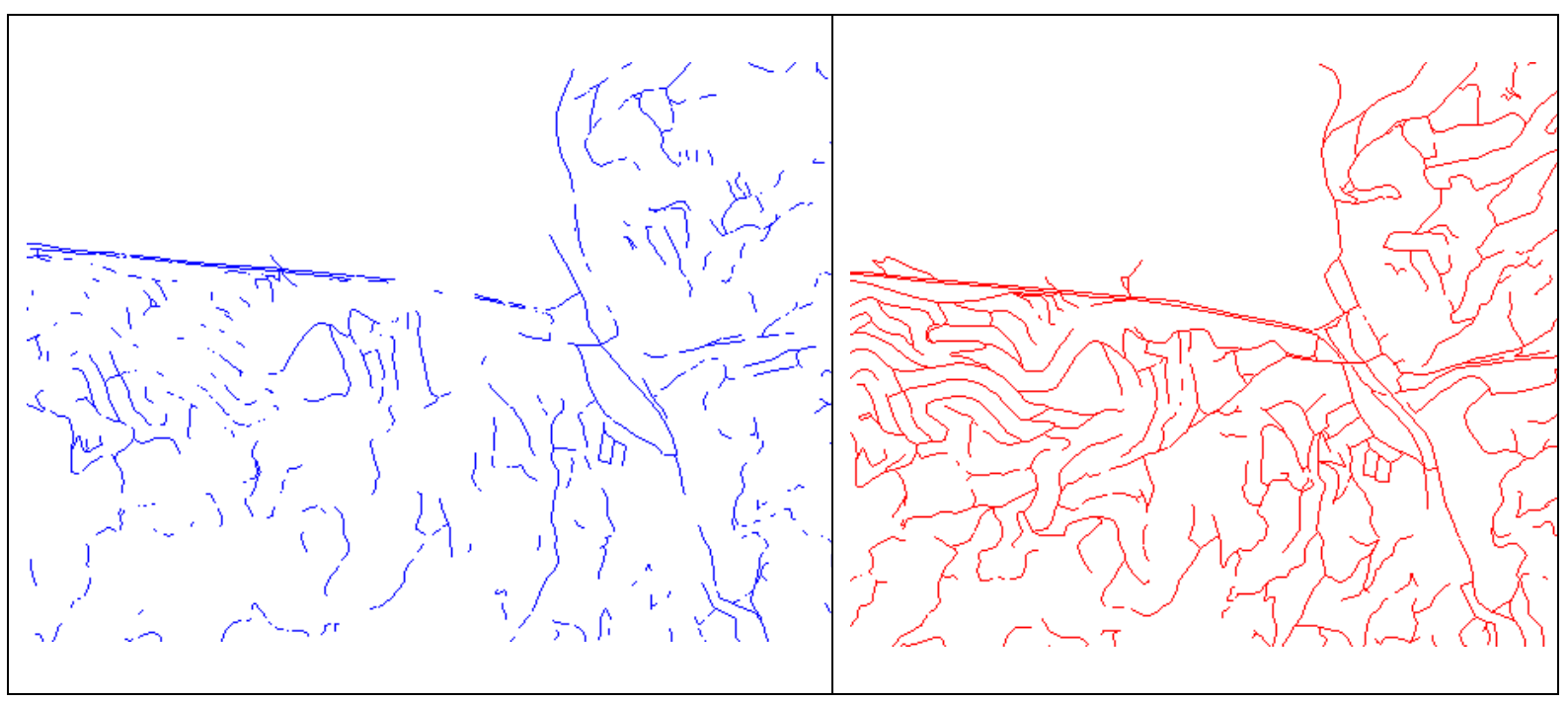

Figure 7. GIS Based analysis of on-screen manual digitizing results of the roads from IKONOS imageries. (2002 is left, 2008 is right).

After extraction, all of the objects numbers and lengths of the roads and also areas were calculated by means of GIS software. These results can be seen in the Table 1 .

\begin{tabular}{|c|c|c|c|c|c|}
\hline \multicolumn{2}{|c|}{$\begin{array}{ll} & \text { Feature } \\
\end{array}$} & $\begin{array}{l}\text { Buildings } \\
\text { (number) }\end{array}$ & $\begin{array}{c}\text { Buildings } \\
\left(\text { area }-\mathbf{m}^{2}\right)\end{array}$ & $\begin{array}{c}\text { Roads } \\
\text { (length - m) }\end{array}$ & $\begin{array}{c}\text { Roads } \\
\left(\text { area } \mathbf{m}^{2}\right)\end{array}$ \\
\hline \multicolumn{2}{|c|}{$\begin{array}{c}\text { Reference data }(1 / 5000 \\
\text { scale) }\end{array}$} & $\begin{array}{c}596 \\
(\% 100)\end{array}$ & $\begin{array}{c}143100.45 \\
(\% 100)\end{array}$ & $\begin{array}{c}14570.31 \\
(\% 100)\end{array}$ & $\begin{array}{c}165037.52 \\
(\% 100)\end{array}$ \\
\hline \multirow{2}{*}{$\begin{array}{c}\text { IKONOS } \\
\text { pan-sharp } \\
(2002)\end{array}$} & Manual & $\begin{array}{c}404 \\
(\% 68) \\
\end{array}$ & $\begin{array}{c}96814.44 \\
(\% 68)\end{array}$ & $\begin{array}{l}8063.66 \\
(\% 55) \\
\end{array}$ & 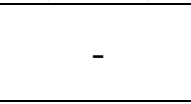 \\
\hline & $\begin{array}{c}\text { Object- } \\
\text { Based }\end{array}$ & $\begin{array}{c}530 \\
(\% 89)\end{array}$ & $\begin{array}{c}123534.14 \\
(\% 86)\end{array}$ & - & $\begin{array}{c}220481.00 \\
(\% 133)\end{array}$ \\
\hline \multirow{2}{*}{$\begin{array}{c}\text { IKONOS } \\
\text { pan-sharp } \\
(2008)\end{array}$} & Manual & $\begin{array}{c}431 \\
(\% 72)\end{array}$ & $\begin{array}{c}112504.76 \\
(\% 79)\end{array}$ & $\begin{array}{c}10096.23 \\
(\% 69)\end{array}$ & 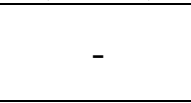 \\
\hline & $\begin{array}{c}\text { Object- } \\
\text { Based }\end{array}$ & $\begin{array}{c}451 \\
(\% 76) \\
\end{array}$ & $\begin{array}{c}138748.31 \\
(\% 97)\end{array}$ & - & $\begin{array}{c}243216.13 \\
(\% 147)\end{array}$ \\
\hline
\end{tabular}

Table 1. Comparable results from the imageries and reference data.

\section{CONCLUSION}

Up to now high resolution digital images and also digital techniques is very important a lot of applications of GIS. For instance, GIS and remote sensing data was executed spatial analysis, DEM generations, updating database and so on. GIS also serve as a lot of components to the governmental agencies and private agencies. Therefore, it is possible to update GIS data for a lots of making decisions operations. For this reason high resolution digital images very important for updating GIS and databases.

In this study, feature extraction approaches and using for updating for GIS were discussed using high resolution images for generation of topographic line mapping. Thus, it can be able to decide which data is applicable for which database updating. Features mentioned above were compared using automatic object-based extraction and manual on-screen digitizing results from IKONOS 
imageries and reference 1:5000 scale topographic maps in study area Firstly, object-based image analysis results of buildings and road network were derived using eCognition v4.0.6 software. Then features mentioned above were digitized manually to compare with reference vector data. For this comparison, on-screen digitizing method was used without field check of extracted objects from the images. Based on the results, IKONOS

\section{REFERENCES}

Baatz, M., Benz, U., Dehghani, S., Heynen, M., Höltje, A., Hofmann, P., Lingenfelder, I., Mimler, M., Sohlbach, M., Weber, M. and Willhauck, G., eCognition Professional: User Guide 5, Munich: Definiens-Imaging, 2004.

Büyüksalih, G., Jacobsen, K., Optimized Geometric Handling of High Resolution Space Images, In: ASPRS annual convention, Baltimore, p.9, 2005

Jacobsen, K., Büyüksalih, G., Marangoz, A., Sefercik, U.G. and Büyüksalih, İ., Recent Advances in Space Technologies (RAST). Istanbul, 2005.

Jacobsen K., Büyüksalih G., Baz I. 2008. Mapping From Space for Developing Countries. Proceedings Earsel imageries generally good results extraction of the buildings. But, IKONOS imageries are not suitable for automatic feature extraction on this study area especially road features. Results based on new imagery with $50 \mathrm{~cm}$ or better GSD could be compared with the results derived from this study for GIS updating. Using digital photogrammetry data would produce more suitable results for GIS applications which require more accuracy.

Joint Workshop: Remote Sensing New Challenges of High Resolution, 5-7 March 2008, Bochum, Germany.

Marangoz, A. M., Alkış, Z., Karakış, S., Evaluation of Information Content and Feature Extraction Capability of Very High Resolution Pan-Sharpened QuickBird Image, Conference on Information Extraction from SAR and Optical Data, with emphasis on Developing Countries, 16-18 May, İstanbul, 2007.

Sefercik, U.G., Oruc, M., Alkan, M., Adaptation of High Resolution Ikonos Images to Googleearth for Zonguldak Test Field, FIG Annual Conference, Stockholm, Sweden, 2008.

Zhang and Wang, Multi-Resolution and Multi-Spectral Image Fusion for Urban Object Extraction, ISPRS XXth Congress, Istanbul, 2004. 